\title{
Influence of cholesterol/caveolin-1/caveolae homeostasis on membrane properties and substrate adhesion characteristics of adult human mesenchymal stem cells
}

Jihee Sohn ${ }^{1}$, Hang Lin ${ }^{1}$, Madalyn Rose Fritch ${ }^{2}$ and Rocky S. Tuan ${ }^{1,2^{*}}$

\begin{abstract}
Background: Adult mesenchymal stem cells (MSCs) are an important resource for tissue growth, repair, and regeneration. To utilize MSCs more effectively, a clear understanding of how they react to environmental cues is essential. Currently, relatively little is known about how the composition of the plasma membranes affects stem cell phenotype and properties. The presence of lipid molecules, including cholesterol in particular, in the plasma membrane plays a crucial role in regulating a variety of physiological processes in cells. In this study, we examined the effects of perturbations in cholesterol/caveolin-1 (CAV-1)/caveolae homeostasis on the membrane properties and adhesive characteristics of MSCs. Findings from this study will contribute to the understanding of how cholesterol/CAV-1/ caveolae regulates aspects of the cell membrane important to cell adhesion, substrate sensing, and microenvironment interaction.
\end{abstract}

Methods: We generated five experimental MSC groups: 1) untreated MSCs; 2) cholesterol-depleted MSCs; 3) cholesterol-supplemented MSCs; 4) MSCs transfected with control, nonspecific small interfering (si)RNA; and 5) MSCs transfected with CAV-1 siRNA. Each cell group was analyzed for perturbation of cholesterol status and CAV-1 expression by performing Amplex Red cholesterol assay, filipin fluorescence staining, and real-time polymerase chain reaction (PCR). The membrane fluidity in the five experimental cell groups were measured using pyrene fluorescence probe staining followed by FACS analysis. Cell adhesion to collagen and fibronectin as well as cell surface integrin expression were examined.

Results: Cholesterol supplementation to MSCs increased membrane cholesterol, and resulted in decreased membrane fluidity and localization of elevated numbers of caveolae and CAV-1 to the cell membrane. These cells showed increased expression of a1, a4, and $\beta 1$ integrins, and exhibited higher adhesion rates to fibronectin and collagen. Conversely, knockdown of CAV-1 expression or cholesterol depletion on MSCs caused a parallel decrease in caveolae content and an increase in membrane fluidity due to decreased delivery of cholesterol to the cell membrane. Cells with depleted CAV-1 expression showed decreased cell surface integrin expression and slower adhesion to different substrates.

(Continued on next page)

\footnotetext{
* Correspondence: tuanrocky@gmail.com

${ }^{1}$ Center for Cellular and Molecular Engineering, Department of Orthopaedic Surgery, University of Pittsburgh School of Medicine, 450 Technology Drive, Room 221, Pittsburgh, PA 15219, USA

${ }^{2}$ Department of Bioengineering, Swanson School of Engineering, University of Pittsburgh, Pittsburgh, PA 15219, USA
} 
(Continued from previous page)

Conclusions: Our results demonstrate that perturbations in cholesterol/CAV-1 levels significantly affect the membrane properties of MSCs. These findings suggest that modification of membrane cholesterol and/or CAV-1 and caveolae may be used to manipulate the biological activities of MSCs.

Keywords: Mesenchymal stem cells, Caveolin-1, Caveolae, Cholesterol, Membrane properties, Membrane fluidity, Cell adhesion

\section{Background}

Regenerative medicine aims to re-establish lost tissue function within complex in vivo environments. Endogenous or exogenous stem cells, such as adult mesenchymal stem cells (MSCs), are an attractive cell source to utilize for effective restoration of tissue function by cell-driven tissue synthesis. MSCs possess the ability to proliferate and differentiate into different cell types, including osteoblasts, adipocytes, and chondrocytes, dependent on their environmental conditions [1-3]. The attractiveness of MSCs stems from their multipotent differentiation potential and relative ease of isolation, in addition to their immunomodulatory properties and release of trophic factors $[4,5]$.

A landmark discovery in stem cell-environment interactions was made by Engler et al. [6] who reported that the stiffness of two-dimensional (2D) adhesion substrates can determine the differentiation of MSCs in vitro. These investigators showed that MSCs differentiate into neurogenic, myogenic, and osteogenic phenotypes on substrates that have elasticity values similar to those of brain, muscle, and bone tissue, respectively [6]. This mechanosensory behavior is a potentially critical parameter in the application of MSCs for tissue engineering. Therefore, to utilize MSCs more effectively, a clear understanding of how they react to environmental cues is essential. While many studies have focused on derivation and molecular regulation of stem cells, relatively little is known about the composition of the stem cell membrane, the organization of which can critically affect cell responses to external stimuli.

Cell membranes represent not only important cellular barriers, but also first-contact structures of the MSCs with their extracellular matrix (ECM). Lipid rafts are cell membrane microdomains that influence the organization of cell signaling molecules [7]. The organization of signaling molecules in MSC membrane lipid rafts likely plays an important role in governing stem cell phenotype and responsiveness to external stimuli. Lipid rafts of cell membranes fall into two broad categories, noncaveolar lipid rafts and caveolae, based on the absence or presence of caveolin proteins, respectively $[8,9]$.

Caveolae are flask-shaped plasma membrane invaginations that are sphingolipid and cholesterol-rich. The defining feature of caveolae is the presence of the protein caveolin $[10,11]$. Caveolin-1 (CAV-1), a scaffolding protein, is the main protein component of caveolae and has been implicated in numerous cellular functions, including cholesterol export, endocytosis, and regulation and organization of cell signaling molecules [11, 12]. Most importantly, CAV-1 binds to cholesterol and drives caveolae formation [13, 14]. Previous studies performed with human skin fibroblasts reported that intracellular cholesterol levels are closely related to CAV-1/caveolae expression and activity. Intracellular accumulation of cholesterol promotes CAV- 1 expression, and CAV- 1 directs the export of cholesterol to caveolae in response to increased intracellular cholesterol uptake or synthesis $[15,16]$. Together, these studies strongly suggest that CAV-1 may also be involved in regulating organization and the distribution of caveolae and lipid membrane rafts. Furthermore, CAV-1 expression may be regulated by cholesterol and/or vice versa. However, in stem cells, CAV-1/caveolae and membrane cholesterol regulation and their functional relationships are incompletely understood and further investigation is required, particularly in MSCs.

Cholesterol is a critical component of the plasma membrane and plays a key role in determining the physical properties of the lipid bilayer [17]. Thus, modification of cell membrane cholesterol, CAV-1, and caveolae contents should affect membrane properties such as fluidity. In fact, cholesterol or lipid integration into the cell membrane has been reported to decrease membrane fluidity in HEK $293 \mathrm{~T}$ cells [18]. In addition, perturbation in membrane cholesterol, CAV-1, and caveolae levels may affect the availability of cell surface adhesion receptors and integrin expression [19], which further affect cell adhesion potentials. Integrins function as a major class of transmembrane cell substrate receptors, consisting of heterodimers of $\alpha$ and $\beta$ subunits that bind to epitopes on different ECM substrates with different degrees of stability $[20,21]$. As the principal adhesive ECM receptors in the cell membrane, the activity of integrins plays a vital role in MSC substrate mechanosensing $[6,22]$. The stability of cell adhesion to different substrates is dependent on the expression profile of integrins on the cell membrane [23, 24]. Fewer cell surface integrins for a particular substrate decrease the stability of cell adhesions due to less abundant/stable 
interactions. Additionally, amplified contractile forces rupture integrin contacts and increase integrin endocytosis, further decreasing cell adhesion [20]. Interestingly, this integrin internalization occurs via cholesterol-rich, CAV1-coated caveolae membrane rafts in MSCs on 2D substrates [25]. Several studies have shown that the endocytic mechanism that regulates $\beta 1$ integrin is mediated by lipid rafts, and that down- or upregulating the lipid raft protein, CAV-1, significantly changes $\beta 1$ integrin endocytosis [25-27]. In addition, CAV-1 can promote activation of signaling proteins in focal adhesions, as well as downregulate it by driving the caveolar endocytosis of focal adhesion proteins $[19,28,29]$, which can further affect integrin function and activity. These studies suggest that if the expression and activity of CAV-1/caveolae is intimately linked with membrane cholesterol status in MSCs, perturbing cholesterol/CAV-1/caveolae in MSCs should affect membrane fluidity, substrate adhesion rate, and cell surface integrin expression. Moreover, the activity of the cholesterol/CAV-1/caveolae system may influence cell mechanosensing, and cholesterol and CAV-1 may be targets for manipulation of MSC responses to physical substrates.

This study was designed to test the effects of perturbations in cholesterol/CAV-1/caveolae homeostasis on human bone marrow-derived MSC membrane properties and adhesive characteristics. To determine the functional relationship of cholesterol and CAV-1/caveolae and their potential influence on MSC activities, we generated five experimental MSC groups: 1) untreated cells serving as control; 2) cholesterol-depleted MSCs; 3) cholesterol-supplemented MSCs; 4) MSCs transfected with control small interfering (si)RNA; and 5) MSCs transfected with CAV-1 siRNA. Each cell group generated was analyzed for perturbations of cholesterol status and CAV-1 expression. Our results showed that perturbations in cholesterol/CAV-1/caveolae levels affect the membrane properties of MSCs. Cholesterol supplementation in the culture medium resulted in increased cell membrane cholesterol content, thus localizing elevated numbers of caveolae and CAV-1 to the cell membrane and, as a result, these cells had decreased membrane fluidity. These cells showed increased expression of $\alpha 1, \alpha 4$, and $\beta 1$ integrins and thus had higher adhesion rates to fibronectin and collagen. Conversely, knockdown of CAV-1 expression or cholesterol depletion on MSCs caused a parallel decrease in the number of cell surface caveolae and an increase in membrane fluidity due to decreased delivery of cholesterol to the cell membrane. Cells with depleted CAV-1 expression showed decreased cell surface integrin expression and demonstrated slow adhesion to different substrates. Taken together, our findings suggest that treatments that increase or decrease membrane cholesterol and/or CAV-1 and caveolae in
MSCs may be used to manipulate the biological activities of MSCs.

\section{Methods \\ Tissue collection and harvesting of MSCs}

Human bone marrow-derived MSCs were isolated with Institutional Review Board approval (University of Washington, Seattle, WA) from the femoral heads of patients undergoing hip arthroplasty using a standard plastic adhesion protocol. Cells flushed from the bone marrow were pelleted and resuspended in isolation medium (ISM) ( $\alpha$-minimum essential medium (MEM) + $1 \times$ antibiotic-antimycotic $+10 \%$ MSC qualified fetal bovine serum (FBS; all Gibco/Thermo Fisher Scientific, Waltham, MA, USA) $+1 \mathrm{ng} / \mathrm{ml}$ fibroblast growth factor (FGF)2 (R\&D Systems, Minneapolis, MN)), seeded into T150 flasks (Corning Inc., Corning, NY, USA) and incubated for 3-4 days at $37{ }^{\circ} \mathrm{C}$ under $5 \% \mathrm{CO}_{2}$, then washed twice with phosphate-buffered saline (PBS; pH 7.4) and incubated in fresh isolated medium. When colonies reached $80 \%$ confluence, cells were harvested with trypsin/EDTA and resuspended at $1 \times 10^{6}$ cells/T150 flask in ISM. Medium was changed every 3-4 days when cells reached $80-90 \%$ confluency, at which time cells were either frozen or passaged. MSC isolates were routinely characterized with respect to multilineage differentiation capabilities as described previously [30]. Multiple donor MSCs were pooled (Additional file 1: Table S1) and used in this study.

\section{Cell culture and treatments Cell culture}

For the experiments, MSCs were expanded in proliferation medium (PM) containing high-glucose Dulbecco's modified Eagle's medium (DMEM) containing L-glutamine and sodium pyruvate $+1 \times$ antibiotic-Antimycotic $+10 \%$ MSC qualified FBS (all Gibco/Thermo Fisher Scientific, Waltham, MA, USA) at $37{ }^{\circ} \mathrm{C}$ under $5 \% \mathrm{CO}_{2}$. PM was changed every 3-4 days until cells reached $70-80 \%$ confluence, at which time cells were seeded for experiments.

\section{Cell membrane cholesterol manipulation}

Disruption to all cholesterol membrane rafts was achieved by 60 -min preincubation with methyl- $\beta$ cyclodextrin (M $\beta C D$; Sigma-Aldrich) in DMEM used at a final concentration of $10 \mathrm{mM}$. As prolonged incubation with $\mathrm{M} \beta C D$ is cytotoxic to MSCs, M $\beta C D$ was not left on cells beyond the 60 -min period. After $M \beta C D$ pretreatment, cholesterol-depleted cells were cultured in fresh medium containing charcoal stripped FBS (CSFBS; Gemini Bio-Products, West Sacramento, CA, USA). CS-FBS has been adsorbed with activated carbon, which removes hormones, phospholipids, and free fatty acid fractions in FBS. The removal of serum free fatty 
acids and lipid-like components has been shown to minimize cell lipid metabolic functions [31].

Cholesterol supplementation was achieved by pretreating MSCs with $10 \mathrm{mM} \mathrm{M} \beta C D$ for $60 \mathrm{~min}$ and then incubating cells with fresh medium containing CS-FBS and $100 \mu \mathrm{M}$ cholesterol-cyclodextrin inclusion complexes. For preparation of the cholesterol-M $\beta C D$ inclusion complexes (chol-M $\beta C D$ ), small aliquots of cholesterol (Sigma-Aldrich) in methanol-chloroform $(2: 1 \mathrm{v} / \mathrm{v})$ were added to a stirred solution of $\mathrm{M} \beta \mathrm{CD}(5 \% \mathrm{w} / \mathrm{v})$ in a water bath $\left(80^{\circ} \mathrm{C}\right) ; 1 \mathrm{~g} \mathrm{M} \beta \mathrm{CD}$ was added to $30 \mathrm{mg}$ cholesterol. The mixtures were stirred at $80{ }^{\circ} \mathrm{C}$ until complete dissolution of the initially precipitating steroid. The complex preparations were then freeze-dried and stored at room temperature.

\section{siRNA transfection}

siRNA transfection was performed as described previously [32]. Briefly, cells were seeded at 20,000 cells $/ \mathrm{cm}^{2}$, incubated overnight, washed in serum-free and antibiotic-free high-glucose DMEM, and transfected with either $50 \mathrm{nM}$ human CAV1 ON-TARGETplus SMARTpool siRNA or $50 \mathrm{nM}$ nontargeting control siRNA ON-TARGETplus Non-targeting SMARTpool siRNA (all Dharmacon/GE Life Sciences, Lafayette, CO, USA) using DharmaFECT1 transfection Reagent (Dharmacon/GE Life Sciences). DharmaFECT1 and each siRNA were prepared at $10 \times$ the final concentration used for transfection in serum-free and antibiotic-free high-glucose DMEM and incubated for $5 \mathrm{~min}$ at room temperature. Each siRNA was then mixed 1:1 with the DharmaFECT1, incubated for $20 \mathrm{~min}$ at room temperature, diluted 1:5 in antibiotic-free PM, and added to washed MSCs at $0.13 \mathrm{ml} / \mathrm{cm}^{2}$. The final volume of DharmaFECT used was $0.08 \mu \mathrm{l} / \mathrm{cm}^{2}$. Twenty-four hours later, the medium was replaced with fresh PM.

\section{Cell proliferation assay}

The number of viable cells in proliferation was assessed using the CellTiter 96 Aqueous One Solution Assay (Promega, Madison, WI), a colorimetric method using 3-(4,5-dimethylthiazol-2-yl)-5-(3-carboxymethoxyphenyl)-2-(4-sulfophenyl)-2H-tetrazolium (MTS). Thirty thousand cells were plated in triplicate on 24-well plates and, $48 \mathrm{~h}$ later, CellTiter 96 Aqueous One Solution was added $(20 \mu \mathrm{l} / 100 \mu \mathrm{l} \mathrm{PM})$. After incubation for $4 \mathrm{~h}$, absorbance at $490 \mathrm{~nm}$ was read using a plate reader.

\section{Cell membrane cholesterol quantification}

Cellular lipids were extracted using a chloroform/methanol (2:1) mixture as described previously [33]. Cell membrane cholesterol levels were quantified with a modified version of a previously described microenzymatic fluorescence assay using the Amplex Red cholesterol assay according to the manufacturer's protocol (ThermoFisher Scientific, Waltham, MA) [34]. This colorimetric assay is based on the reaction of cholesterol with cholesterol oxidase to yield $\mathrm{H}_{2} \mathrm{O}_{2}$ which can be detected using the Amplex Red reagent. This method includes treatment with cholesterol oxidase to ensure the exclusive determination of free cholesterol present in the plasma membrane, and not of cholesterol esters present in the cytoplasm. Values of total cholesterol concentration were normalized to total cell number.

\section{mRNA extraction and real-time reverse transcription polymerase chain reaction}

Total RNA was obtained from MSCs using Trizol reagent (Invitrogen, Carlsbad, CA) and an RNeasy Mini Kit (Qiagen, Valencia, CA) according to the manufacturer's instructions. Reverse transcription was performed using a Maxima first strand cDNA synthesis kit (ThermoFisher Scientific) according to the manufacturer's protocol. Polymerase chain reaction (PCR) was performed using an SYBR Green PCR master mix (Applied Biosystems, Foster City, CA) on a 7900HT Fast Real-Time PCR machine (Applied Biosystems) as previously described [32]. The primer sequences used were as follows (Life Technologies, Carlsbad, CA): GAPDH, forward CAAGGCTGAGA ACGGGAAGC, reverse AGGGGGCAGAGATGATGACC; and $C A V-1$, forward GGGCAACATCTACAAGCCCA ACAA, reverse CTGATGCACTGAATCTCAATCAGGAA.

\section{Fluorescent staining}

Cells were seeded onto a 24-well glass bottom plate (Cellvis, Mountain View, CA) and fixed with $4 \%$ paraformaldehyde (PFA) for $1 \mathrm{~h}$ at room temperature. Cells were rinsed with PBS and incubated with $1 \mathrm{ml}$ glycine $(1.5 \mathrm{mg} / \mathrm{ml} \mathrm{PBS})$ for $10 \mathrm{~min}$ at room temperature to quench the PFA. Cells were stained with freshly prepared $50 \mu \mathrm{g} / \mathrm{ml}$ filipin III (Sigma) in PBS for $3 \mathrm{~h}$ at room temperature followed by Alexa Fluor 488 Phalloidin (Life Technologies/Molecular Probes, Eugene, OR; 1:50) in PBS. Stained cells were viewed on an Olympus Fluoview 500 confocal microscope (Olympus America, Inc., Center Valley, PA).

\section{Sucrose gradient subcellular fractionation}

Subcellular fractionation was performed according to a previously published method [35]. Briefly, MSCs were homogenized in $2 \mathrm{ml}$ ice-cold $500 \mathrm{mM}$ sodium carbonate, $\mathrm{pH}$ 11.0, supplemented with protease and phosphatase inhibitors (1:100, Sigma-Aldrich), sonicated (three times, $20 \mathrm{~s}$ each) on ice, mixed 1:1 with $90 \%$ sucrose in MBS buffer (50 mM MES, pH 6.5, $0.3 \mathrm{mM} \mathrm{NaCl}$ ), and placed at the bottom of a $14 \times 89 \mathrm{~mm}^{2}$ ultracentrifuge tube (Beckman, Palo Alto, CA). After the sucrose gradient was formed by layering $4 \mathrm{ml} 35 \%$ sucrose in $1: 1$ 
MBS:500 mM sodium carbonate, followed by $4 \mathrm{ml} 5 \%$ sucrose in 1:1 MBS:500 mM sodium carbonate, samples were centrifuged at $39,000 \mathrm{rpm}$ in a Beckman XL-70 Ultracentrifuge (SW40Ti rotor) for $22 \mathrm{~h}$ at $4{ }^{\circ} \mathrm{C}$. The contents of the centrifuge tubes were collected in sequential 1-ml fractions from top to bottom to make a total of 12 fractions.

\section{Western blotting}

Cell lysates from 12 fractions of the sucrose gradient subcellular fractionation were used for Western blotting. Proteins were analyzed by SDS-PAGE in a $12 \%$ polyacrylamide gel and transferred to polyvinylidene fluoride (PVDF) blots which were blocked in $5 \%$ bovine serum albumin (BSA; Sigma) in Tris-buffered saline $+0.05 \%$ Tween 20 (TBST), and then incubated overnight at $4{ }^{\circ} \mathrm{C}$ with rabbit anti-CAV-1 (1:1000 in TBST $+2.5 \%$ BSA; Abcam). The secondary antibody was Amersham ECL donkey anti-rabbit horseradish peroxidase (HRP)-linked IgG antibody (GE Healthcare UK Limited, Little Chalfont, UK). HRP activity was detected using Super Signal West Dura, Extended Duration Substrate (ThermoScientific $^{\text {tw }}$ Pierce ${ }^{\text {tw }}$ Protein Biology) and the chemiluminescence reaction was visualized using a FOTO/Analyst FxCCD imaging system (Fotodyne Inc., Hartland, WI, USA).

The intensity of bands on Western blots was measured using grayscale images in Image J software (http://imagej.nih.gov/ij) as described previously [32]. Intensities of CAV-1 bands were normalized to the total protein concentration from the same sample. Total protein concentration before sucrose gradient subcellular fractionation was determined by BCA assay (Pierce Biotechnology, Rockford, IL) according to the manufacturer's protocol.

\section{Membrane fluidity}

Membrane fluidity of MSCs was measured by flow cytometry using a fluorescent labeling method according to the manufacturer's protocol (Membrane Fluidity kit, Abcam). Briefly, 200,000 cells were stained at room temperature with the fluorescent lipid reagent containing pyrenedecanoic acid, which exists as either a monomer or an excimer, the latter being formed upon monomer spatial interaction, resulting in a substantial red shift of the emission spectrum of the pyrene probe. A fluorescence-activated cell sorting (FACS) instrument (FACSAria II SORP, Becton Dickenson), equipped with an argon ion laser (360 $\mathrm{nm}$ emission, $60 \mathrm{~mW}$ output) and bandpass filters of $395 \mathrm{~nm}$ (26 nm bandwidth) and $450 \mathrm{~nm}$ (50 nm bandwidth), was used for analyzing the fluorescence intensity of labeled cells. Quantitative monitoring of the membrane fluidity was attained by measuring the ratio of monomer to excimer fluorescence.

\section{Cell adhesion assay}

A cell adhesion assay was performed using the Vybrant Cell Adhesion Assay Kit (V-13181, ThermoFisher Scientific) according to the manufacturer's protocol. Briefly, MSCs were stained with calcein AM solution (final concentration at $5 \mu \mathrm{M}$ ) by incubation at $37^{\circ} \mathrm{C}$ for $30 \mathrm{~min}$, and 5000 cells were plated into prepared tissue culture plastic, collagen I-coated, or fibronectin-coated 96-well microplates. After incubation at $37{ }^{\circ} \mathrm{C}$ for $45 \mathrm{~min}$ to 4.5 $\mathrm{h}$, nonadherent calcein-labeled cells were removed by careful washing, and $200 \mu \mathrm{l}$ PBS was added to each well. The fluorescence intensity of each well was measured using a fluorescein filter set $(494 \mathrm{~nm}$ absorbance maximum and $517 \mathrm{~nm}$ emission maximum). The total fluorescence intensity of plated cells was obtained by omitting the wash steps. The percentage of adhesion was determined by dividing the fluorescence of adherent cells by the total corrected fluorescence of cells added to each microplate well and multiplying by $100 \%$.

\section{Flow cytometry}

One hundred thousand MSCs were collected, washed with PBS containing 2\% FBS, centrifuged, and then placed on ice. The cells were then resuspended in 10\% FBS in PBS and incubated for $10 \mathrm{~min}$. Phycoerythrin $(\mathrm{PE})$-conjugated mouse anti-human CD49a ( $\alpha 1$ integrin, 559,596, BD), allophycocyanin (APC)-conjugated mouse anti-human CD49d ( $\alpha 4$ integrin, 559,881, BD), or APCconjugated mouse anti-human CD29 ( $\beta 1$ integrin, $559,883, \mathrm{BD})$ was added to each tube $(15 \mu \mathrm{l} / 100,000$ cells) and incubated for $30 \mathrm{~min}$ on ice. The cells were then rinsed in $300 \mu \mathrm{l}$ cold washing buffer (2\% FBS in PBS, $4{ }^{\circ} \mathrm{C}$ ). The single color antibody was used to optimize fluorescence compensation settings for multicolor analyses of the cell by flow cytometry. Appropriate control mouse Ig isotype was also used for comparison.

\section{Statistical Analysis}

Figures and statistics were generated using GraphPad 7. All data are presented as means and 95\% confidence intervals for analyzing correlation of gene expression. Otherwise, mean differences between groups were assessed with a Student's $t$ test. Results are given as the mean $\pm \mathrm{SD}$. When more than two groups were analyzed, one-way analysis of variance (ANOVA) was used to calculate statistical significance. $P$ values less than 0.05 were considered significant.

\section{Results}

\section{Generating five experimental groups of MSCS}

For all assays, five experimental MSC groups were generated by disrupting either cell membrane cholesterol or CAV-1 mRNA expression in cells. We depleted cholesterol with $\mathrm{M} \beta C D$, which binds to cholesterol and strips 
cholesterol from the cell membrane. MSCs were transfected with siRNA specific to CAV-1 to downregulate CAV-1 gene expression [32, 36]. The five experimental groups of MSCs were: 1) untreated MSCs; 2) cholesteroldepleted MSCs (MBCD-MSCs); 3) cholesterol-enriched MSCs (Chol-MSCs); 4) MSCs transfected with control, nonspecific siRNA (si Ctrl-MSCs); and 5) MSCs transfected with CAV-1 siRNA (si CAV-1-MSCs).

\section{Setting of cholesterol depletion and supplementation conditions}

$\mathrm{M} \beta \mathrm{CD}$ is currently the most commonly used cyclodextrin for cell membrane cholesterol removal and supplementation studies because of its effectiveness at significantly lower concentrations than other cyclodextrins, although the degree of cholesterol depletion varies based on concentrations of $\mathrm{M} \beta C D$, incubation time, temperature, and cell types [37]. Therefore, initial testing was performed to establish the desired conditions for $\mathrm{M} \beta C D$-mediated cholesterol depletion from the plasma membrane of human MSCs. Cells were first exposed to different concentrations $(2.5-15 \mathrm{mM})$ of $\mathrm{M} \beta C D$ for 40 min (Fig. 1a); $10 \mathrm{mM}$ and $15 \mathrm{mM} \mathrm{M} B C D$ treatments significantly removed membrane cholesterol by $47.0 \%$ and $74.3 \%$, respectively. However, the $15 \mathrm{mM} \mathrm{M \beta CD}$ treatment affected cell viability (data not shown). Additional time course testing using $10 \mathrm{mM} \mathrm{M} \beta C D$ showed that a 60 -min treatment was able to remove $50.8 \%$ cholesterol whilst keeping cell viability almost unchanged (Fig. $1 \mathrm{~b}$ and $\mathrm{d}$ ).

To observe membrane cholesterol recovery time after $60 \mathrm{~min}$ of $10 \mathrm{mM} \mathrm{M} \beta C D$ treatment, the treated cells were then incubated in fresh PM containing CS-FBS for 48 to 72 h. Membrane cholesterol levels slowly recovered but remained significantly lower than those in untreated cells (Fig. 1c).

For cholesterol enrichment, cells were pretreated with $10 \mathrm{mM} \mathrm{M} \beta C D$ for $60 \mathrm{~min}$ and then exposed to cholesterol-M $B C D$ inclusion complexes (chol-M $B C D$ ). Compared to untreated MSCs, $100 \mu \mathrm{M}$ chol-M $\beta C D$ loading led to a significant increase in membrane cholesterol levels. After $3 \mathrm{~h}$ of incubation with chol-M $\beta C D$, the
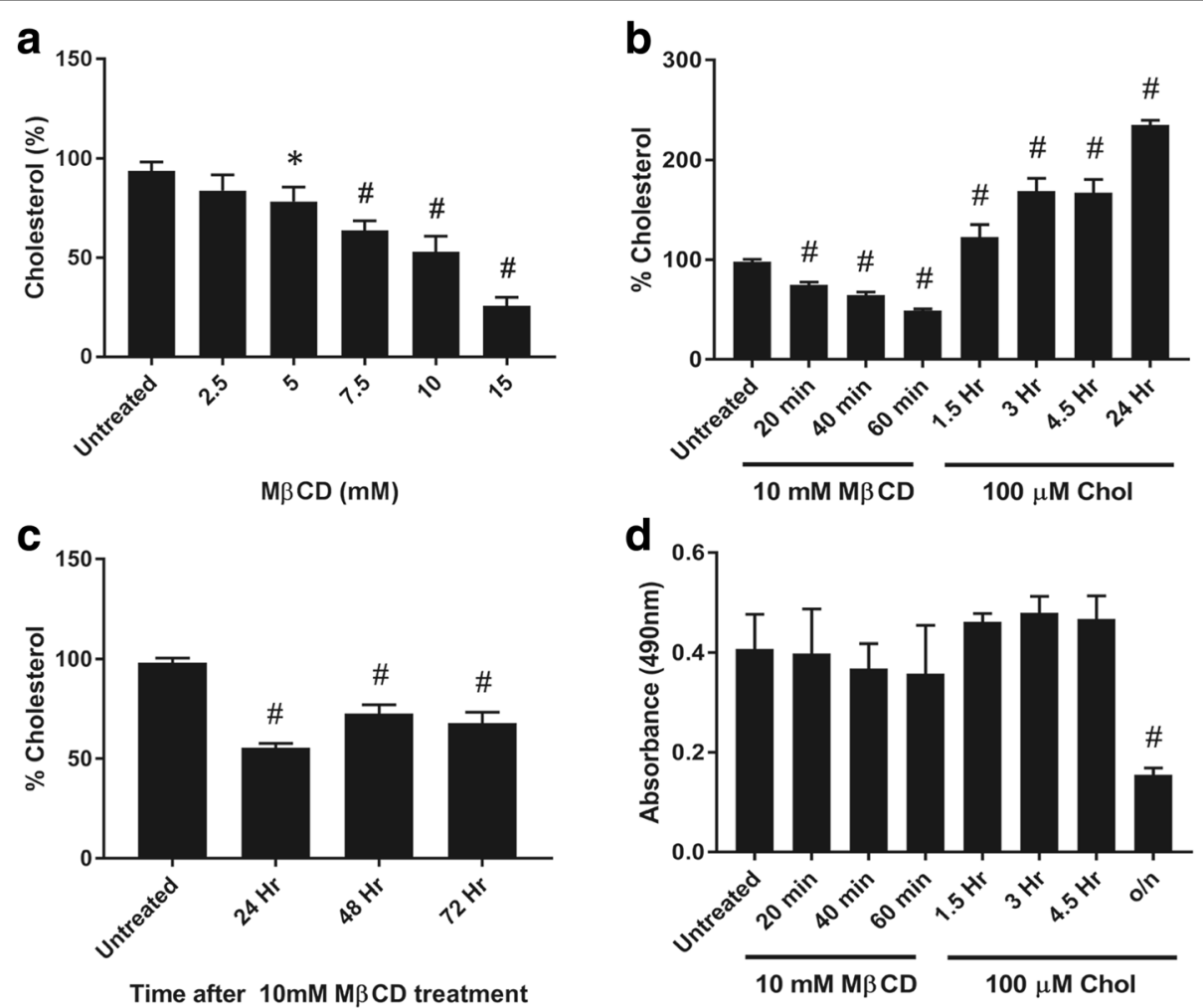

Fig. 1 Effects of methyl- $\beta$-cyclodextrin (MBCD) and cholesterol (chol)-M $\beta C D$ treatments on membrane cholesterol level and cell viability of MSCs. a Cholesterol level of MSCs after treatment with MBCD for $40 \mathrm{~min}$ at the concentrations indicated. Membrane cholesterol levels were measured and compared (untreated cells $=100 \%$ ). $\mathbf{b}$ Cholesterol level of MSCs after treatment with $10 \mathrm{mM} \mathrm{MBCD}$ or $100 \mu \mathrm{M}$ chol-MBCD for the time indicated. c Time course of cholesterol level of MSCs after initial treatment with $10 \mathrm{mM} \mathrm{MBCD}$ for 60 min. After treatment, cells were washed with PBS and incubated in fresh PM containing CS-FBS for the time indicated. $\mathbf{d}$ Viability of cells, treated as described in Fig. 1b, evaluated by MTS assay. Results are presented as mean $\pm S D ; n \geq 3$ independent experiments per cell line per time point. The results showed the effectiveness of M $M C D$ and chol-M $M C D$ in altering MSC membrane cholesterol level without compromising cell viability. ${ }^{*} p<0.05,{ }^{*} p<0.0001$, versus untreated group. o/n overnight 
membrane cholesterol levels increased by $169.1 \%$ without affecting cell viability (Fig. 1b and d). Longer incubation with chol-M $\beta C D$ decreased cell viability (Fig. 1d).

Based on the results that showed that $10 \mathrm{mM} \mathrm{M} \beta C D$ treatment decreased about $50 \%$ of membrane cholesterol and that $100 \mu \mathrm{M}$ chol-M $\mathrm{MCD}$ loading increased about $170 \%$ of membrane cholesterol, these conditions were used throughout this study to manipulate membrane cholesterol levels in MSCs.

\section{Effect on CAV-1 mRNA}

The five experimental cell groups were analyzed for the relationship between perturbation of cholesterol status and CAV-1 expression. Quantitative reverse transcription PCR analysis showed that cholesterol enrichment resulted in increased CAV-1 mRNA expression, while cholesterol depletion resulted in decreased CAV-1 mRNA expression, compared with untreated MSCs (Fig. 2a). As expected and based on our previous findings [32, 36], si CAV-1-MSCs showed significantly decreased CAV-1 gene expression (Fig. 2b) compared with si Ctrl-MSCs, lasting up to 8 days after transfection (data not shown). Taken together, these results showed that CAV-1 mRNA levels are responsive to membrane cholesterol levels, suggesting a functional correlation between free membrane cholesterol and CAV-1 gene expression in MSCs.

\section{Effect on membrane cholesterol levels}

As expected, cell membrane cholesterol analysis of the five MSC experimental groups showed higher cholesterol concentrations in Chol-MSCs (188.7\% increase) compared with untreated groups, while $\mathrm{M} \beta \mathrm{CD}$ treatment removed $48.1 \%$ of membrane cholesterol from MSCs. Knockdown of CAV-1 expression also caused a significant decrease in cell membrane cholesterol $(24.8 \%$ decrease) compared with si Ctrl-MSCs (Fig. 3a).
Filipin fluorescence staining for free membrane cholesterol was next performed in cultured MSCs, and the staining pattern was observed by confocal microscopy (Fig. 3b). Consistent with the biochemical assays, fluorescence images that represent cellular cholesterol distribution in the five MSC groups indicated increased free membrane cholesterol staining upon cholesterol enrichment, while knockdown of CAV-1 gene and cholesterol depletion caused a decrease in cell membrane cholesterol staining. Furthermore, we observed that CAV-1 siRNA treatment reduced both CAV-1 mRNA levels (Fig. 2b) and membrane free cholesterol (Fig. 3), again supporting a link between membrane cholesterol and CAV-1 expression and level in MSCs.

\section{Effect on caveolae content}

CAV-1 is the major protein component of caveolae and, in fact, formation and expression of caveolae and CAV-1 are highly dependent on the availability of cholesterol [38]. We therefore analyzed membrane caveolae content in the five experimental MSC groups. Protein samples were harvested and sucrose density gradient subcellular fractionation followed by Western blotting of each fraction for CAV-1 was performed. These results were used as an indication of cell caveolae content [39]. As we showed in a previous study, CAV-1 protein was detected in the buoyant lipid raft containing fractions 4 to 7 obtained by sucrose density gradient fractionation [32] (Fig. 4a). Cholesterol enrichment resulted in increased CAV-1 protein expression, an indication of elevated cell caveolae content. On the other hand, cholesterol depletion and knockdown of CAV-1 gene resulted in decreased CAV-1 protein expression, indicating decreased cell caveolae content (Fig. 4a, b). Taken together, these results provide further evidence that regulation of membrane cholesterol is closely associated with the caveolae, which may be mediated by CAV-1 mRNA.
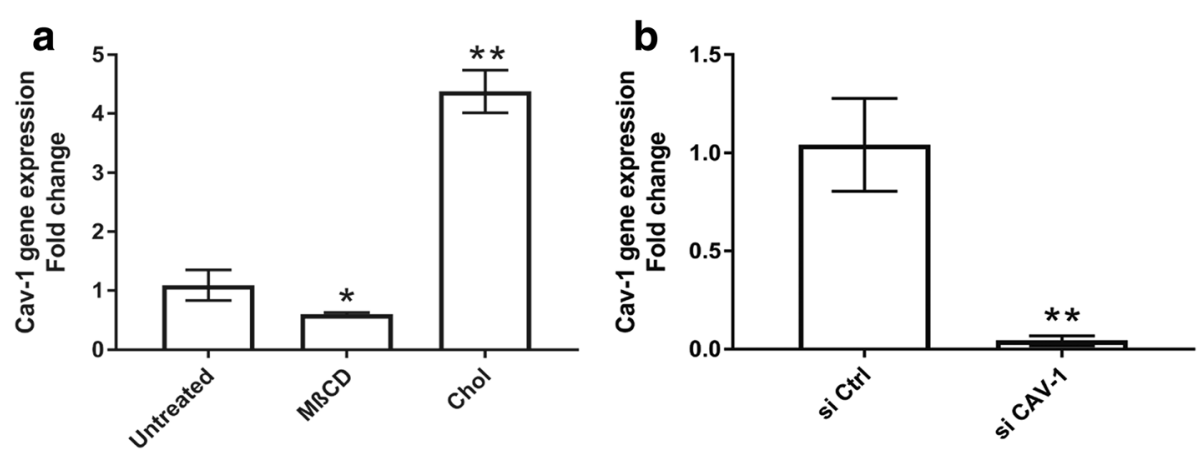

Fig. 2 Effects of membrane cholesterol perturbation on CAV-1 mRNA expression. a Untreated, cholesterol-depleted MSCS (MBCD), and cholesterol-enriched MSCs (Chol) groups, and $\mathbf{b}$ control siRNA (si Ctrl) and caveolin-1 siRNA (si CAV-1) treated groups. RNA was extracted from freshly collected MSCs of the five experimental groups and the CAV-1 mRNA level was assessed by real time reverse transcription PCR. The data represent the mean and 95\% confidence intervals of the fold-change relative to the untreated or si Ctrl group; $n=9$. These results showed that CAV-1 mRNA expression was affected by the membrane cholesterol level and confirmed effective siRNA-mediated knockdown of CAV-1 gene expression in MSCs. ${ }^{*} p<0.005,{ }^{* *} p<0.0001$, versus untreated or si Ctrl group 

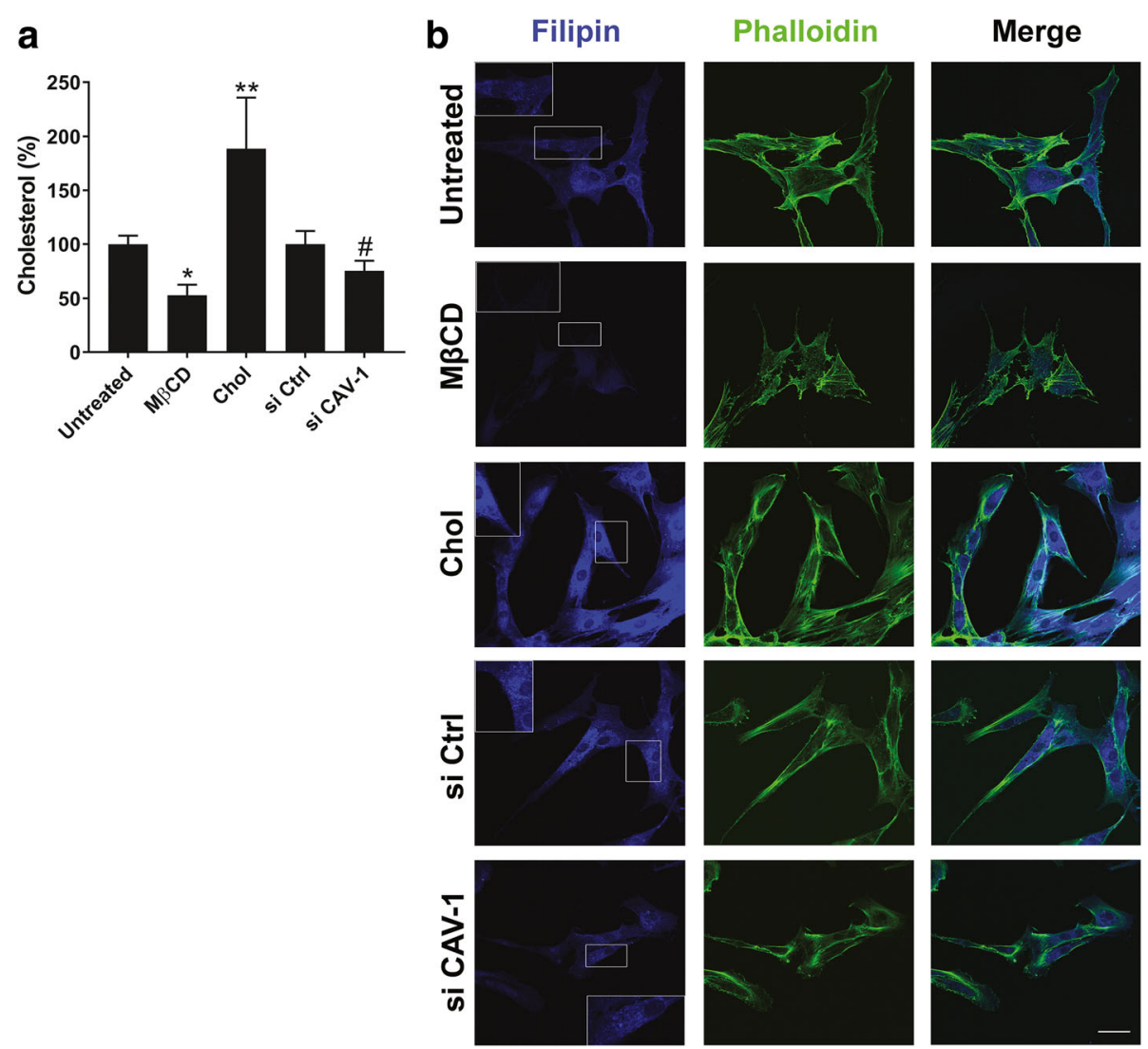

Fig. 3 Effects of membrane-specific cholesterol and caveolin-1 (CAV-1) perturbation on membrane cholesterol levels in five MSC experimenta groups: untreated MSCs, cholesterol-depleted MSCs (MBCD), cholesterol-enriched MSCs (Chol), MSCs transfected with control, nonspecific siRNA (si Ctrl), and MSCs transfected with CAV-1 siRNA (si CAV-1). a Membrane cholesterol content in washed cells was measured and quantified using the Amplex red cholesterol assay and compared with untreated or si Ctrl cells (100\%). Data represent mean \pm SD; $n=9 .{ }^{*} p<0.005,{ }^{* *} p<0.001$, versus untreated group; ${ }^{\#} p<0.05$, versus si Ctrl group. b Cells were fluorescently stained with filipin for cholesterol (blue) and phalloidin for filamentous actin (green). The scale bar shown represents $50 \mu \mathrm{m}$ and applies to all panels; $(n>4)$. These results showed that siRNA-mediated knockdown of CAV-1 gene expression significantly decreased membrane cholesterol levels in MSCs

\section{Effect on cell membrane fluidity}

Perturbation in cell membrane cholesterol is known to affect cell membrane fluidity [18]. Results obtained using the Abcam fluorescence-based pyrene probe showed that cholesterol and CAV-1 depletion increased membrane fluidity, while cholesterol enrichment decreased membrane fluidity in MSCs (Fig. 5).

\section{Effect on cell adhesive properties}

To assess whether modification of cholesterol content in MSCs could affect MSC adhesion to different substrates, the adhesion kinetics of the five MSC groups to collagen I (CL), fibronectin (FN), and plain cell culture plastic (PL) were measured. As expected, cells adhered more efficiently to $\mathrm{CL}$ and FN compared with PL (Fig. 6). The removal of cholesterol from the cell membrane significantly decreased adhesion level (at 45 min: 28\%, 26\%, $18 \%$ for CL, FN, and PL, respectively), while cholesterol enrichment increased cell adhesion (at 45 mins: 54\%,
$52 \%, 50 \%$ for $\mathrm{CL}, \mathrm{FN}$, and PL, respectively) compared with no treatment (at 45 mins: 43\%, 40\%, 35\% for CL, FN, and PL, respectively) (Fig. 6a-c). The elimination or supplementation of cholesterol in MSCs seemed to affect cell adhesion to $\mathrm{CL}$ and FN to similar degrees (Fig. 6b, c). Knockdown of CAV-1 gene also decreased adhesion rate of cells to CL and FN (Fig. 6e, f); however, it did not affect the cell adhesion rate on PL (Fig. 6d).

\section{Effect on cell surface integrin levels}

The observed increased adhesion rate of MSCs to CL and FN compared with PL (Fig. 6) prompted us to profile the expression of cell surface integrin receptors for collagen and fibronectin, specifically integrins $\alpha 1, \alpha 4$, and $\beta 1$ [40]. Interestingly, flow cytometry results demonstrated that the percentage of integrin $\alpha 1-, \alpha 4-$, and $\beta 1$-positive cells in a population was not affected as a result of cholesterol or CAV-1 gene level changes (Fig. 7a). However, the mean fluorescence intensities of $\alpha 1, \alpha 4$, and $\beta 1$ integrin staining 

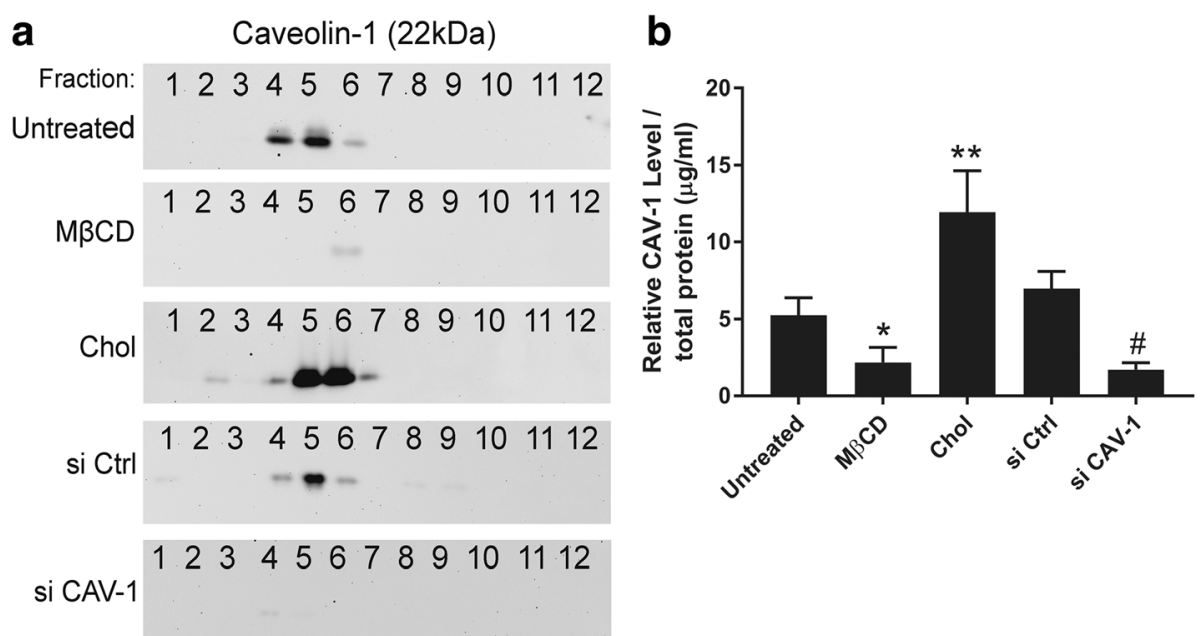

Fig. 4 Effects of cholesterol and caveolin-1 (CAV-1) perturbation on caveolae content in MSCs. Sucrose density centrifugation was used to fractionate membrane preparations derived from the five MSC groups: untreated MSCs, cholesterol-depleted MSCs (MBCD), cholesterol-enriched MSCS (Chol), MSCS transfected with control, nonspecific siRNA (si Ctrl), and MSCs transfected with CAV-1 siRNA (si CAV-1). Upon ultracentrifugation, buoyant membrane rafts float to the upper fractions (4-7) of the 12-fraction sucrose gradient and are separated from intracellular fractions (9-12). Caveolae are identified on the basis of CAV-1 content. a CAV-1 immunoblotting of the fractions. This result is representative of three, pooled human MSC donor sources tested (Additional file 1: Table S1). $\mathbf{b}$ CAV-1 signal/total protein amount used for fractionation for each experimental group analyzed by densitometry. Data represent mean \pm SD of all experimental replicates, analyzed using $\mathrm{NIH}$ Image; $n>3$. These results indicate that changes in membrane cholesterol levels significantly affect the caveolae content in MSCs. ${ }^{*} p<0.05,{ }^{* *} p<0.001$, versus untreated group; ${ }^{*} p<0.001$, versus si Ctrl group

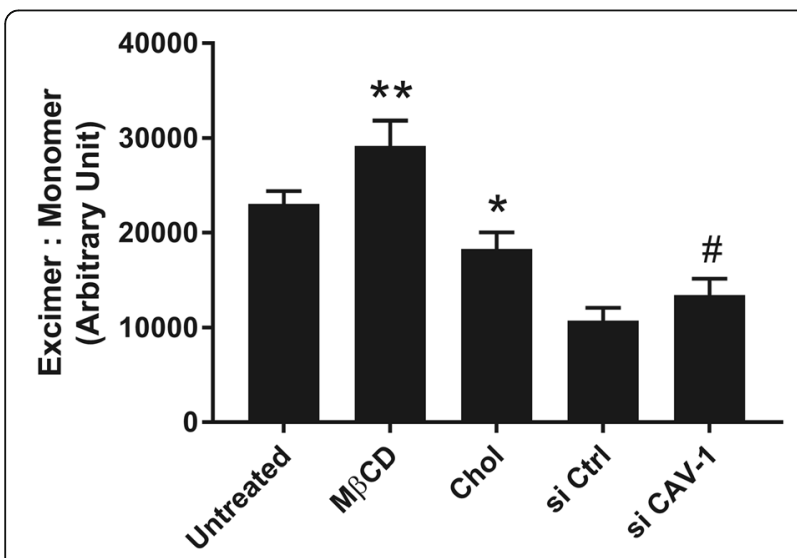

Fig. 5 Effects of cholesterol and caveolin-1 (CAV-1) perturbation on membrane fluidity. FACS analysis based on the relative fluorescence intensities of excimer and monomer to assess membrane fluidity was performed on the five MSC experimental groups: untreated MSCs, cholesterol-depleted MSCS (MBCD), cholesterol-enriched MSCs (Chol), MSCs transfected with control, nonspecific siRNA (si Ctrl), and MSCs transfected with CAV-1 siRNA (si CAV-1). Results are presented as mean $\pm \mathrm{SD} ; n \geq 3$ independent experiments per cell line. The findings show that membrane fluidity is inversely related to membrane cholesterol content, and dependent on the presence of CAV1. ${ }^{*} p<0.05,{ }^{* *} p<0.001$, versus untreated group; ${ }^{\#} p<0.05$, versus si Ctrl group per cell were statistically higher on Chol-MSCs and lower on M $\beta C D-M S C s$ compared with untreated cells (Fig. 7b-d). The levels of integrin $\alpha 1, \alpha 4$, and $\beta 1$ staining per cell were significantly lower in si CAV-1-MSCs compared to si Ctrl-MSCs (Fig. 7b-d). This finding demonstrates that, although cells with different membrane cholesterol contents expressed $\alpha 1, \alpha 4$, and $\beta 1$ integrins at the same ratio (approximately $95-99 \%$ ), the level of expression per cell was higher on cholesterol-rich MSCs.

\section{Discussion}

In this study, we present findings showing that perturbations in membrane cholesterol/CAV-1/caveolae homeostasis significantly affect MSC membrane properties and adhesion characteristics. Specialized membrane lipid rafts, called caveolae, are rich in cholesterol and CAV-1 protein [9]. Recently, relations and interactions between CAV-1/caveolae and membrane cholesterol, the main structural components of lipid rafts, are of considerable interest in cell biology. The present study provides evidence for the first time that the two major components of lipid rafts, CAV-1/caveolae and membrane cholesterol, are directly and functionally linked to each other in human MSCs. CAV-1 mRNA levels and caveolae formation are upregulated by free cholesterol loading and downregulated by membrane cholesterol depletion. Furthermore, CAV-1 siRNA-mediated knockdown reduces both CAV-1 mRNA expression and membrane cholesterol level in MSCs (Figs. 2-4). Consistent with 


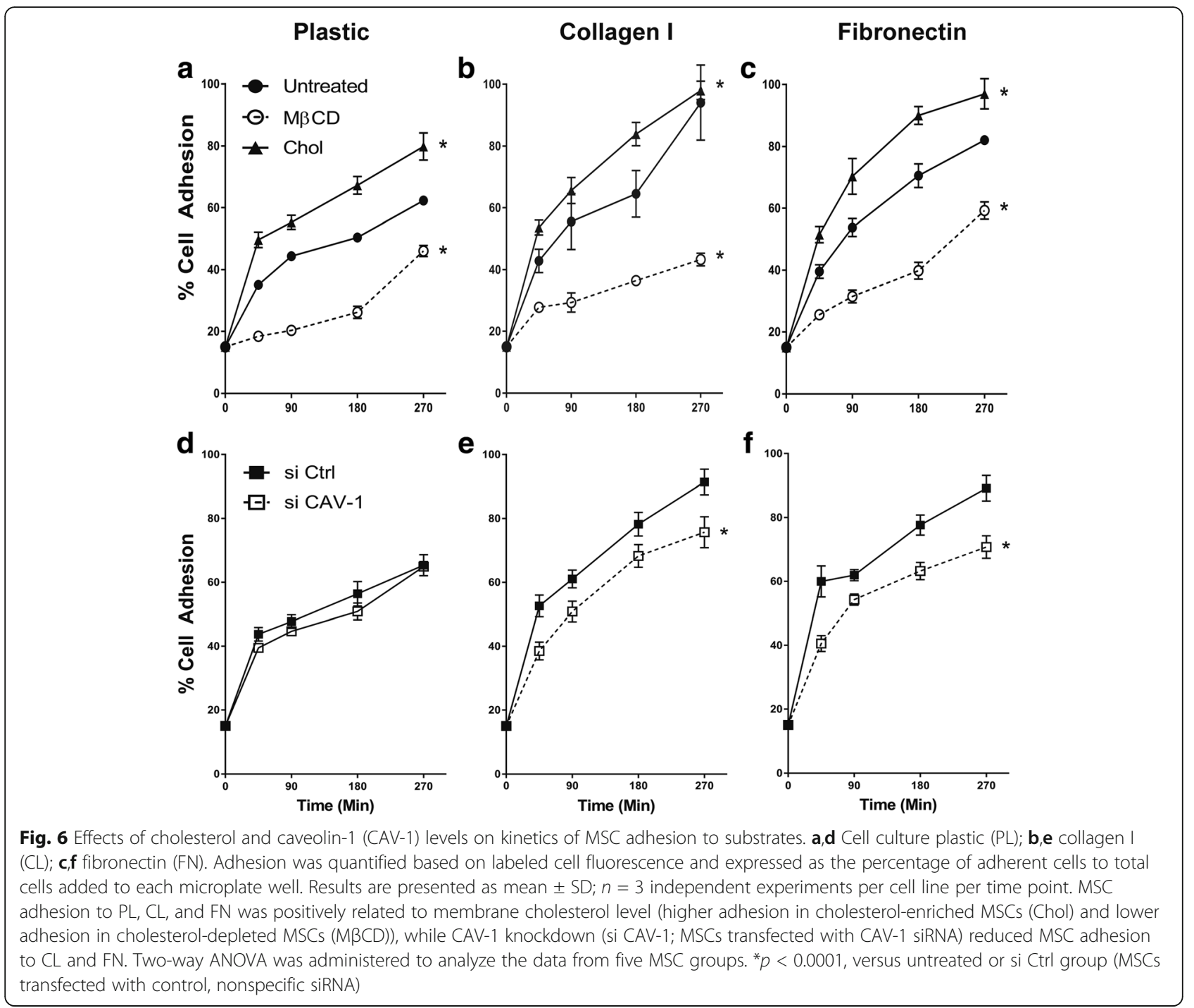

previous studies performed on fibroblasts $[15,16]$, we observed that the membrane cholesterol level is regulated by CAV-1-mediated caveolar pathways in MSCs. Although the mechanism behind these actions is unknown, membrane cholesterol may regulate the CAV-1 transcription via modulating the phosphoinositide 3-kinase (PI3K)/Akt signaling pathways. It has been reported that $\mathrm{M} \beta C D$-mediated cholesterol depletion in cells significantly inhibited the activation of Akt and further reduced PI3K activation, suggesting that the membrane cholesterol level may regulate the PI3K activity [41]. More recently, another study has reported that the PI3K/Akt signaling pathway may be directly involved in CAV-1 mRNA and protein expressions in embryonic stem cells [42]. Taken together, these findings suggest that membrane cholesterol may regulate the CAV-1 transcription level via modulating PI3K/Akt signaling in MSCs. Furthermore, our results suggest that caveolae and caveolin protein levels in the cell may determine lipid raft composition and organization by regulating membrane cholesterol content. Of note, our study was designed to investigate the effect of plasma membrane cholesterol alone by minimizing cholesterogenesis, the effect of intracellular cholesterol biosynthesis. Therefore, it is concluded that changes in membrane cholesterol and CAV-1 mRNA levels in MSCs after perturbation of cholesterol/CAV-1/caveolae homeostasis are not affected by changes in intracellular cholesterol levels.

Another interesting finding of this study is that interactions between cholesterol and CAV-1 protein may influence caveoliogenesis, the formation of morphologically identifiable caveolae. Treatment of cells with $\mathrm{M} \beta C D$ results in significantly lower caveolae content, while cholesterol enrichment results in significantly higher caveolae content (Fig. 4a, b), with concomitant upregulation of CAV-1 mRNA expression (Fig. 2a). In agreement 


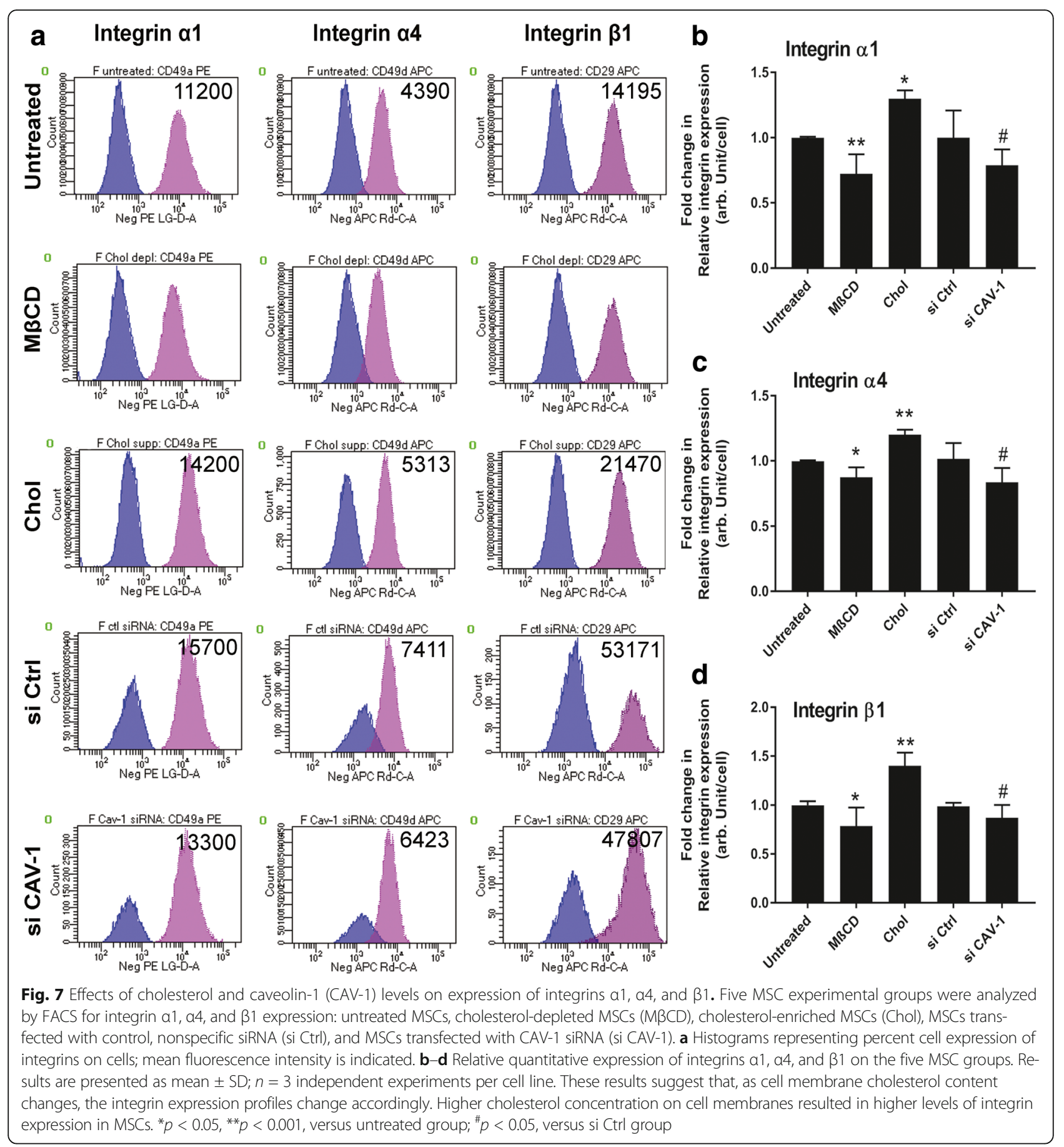

with previous studies performed by others [38, 43], our results indicate that cholesterol may play a crucial role in caveolae development, although further investigation is required to determine the mechanistic steps responsible for this observation. To date, CAV-1 protein expression is generally assumed to be essential and sufficient for caveolae formation; however, previous studies [38, 43, 44] and results from the current investigation suggest that formation of stable caveolae may depend on the interactions between cholesterol and CAV-1 protein. It is also possible that cellular membrane cholesterol levels can function as a determinant of CAV-1 gene and caveolae abundance in MSCs.

Perturbation of cholesterol/CAV-1/caveolae homeostasis in MSCs also shows a profound effect on membrane rigidity/fluidity. Our findings showed that depletion or 
enrichment of membrane cholesterol significantly increased or decreased membrane fluidity, respectively. More importantly, si CAV-1-MSCs showed significantly increased membrane fluidity compared with si CtrlMSCs (Fig. 5). Taken together, these results confirm and ascertain that knockdown of CAV-1 mRNA in MSCs causes a reduction in cholesterol concentration in the plasma membrane. Importantly, these findings suggest that regulating CAV-1 mRNA levels in MSCs alone can be used to control cell membrane fluidity. Interestingly, siRNA transfection alone appears to have an impact on membrane fluidity as membrane fluidity was significantly lower in si Ctrl-MSCs compared with untreated MSCs $(p<0.0001$; Fig. 5$)$, most likely due to the presence of lipofectamine in cells during siRNA transfection. Exposing cells to a lipid-based transfection reagent may cause the transient increase in integration of lipid components to the cell membrane, leading to a reduction in membrane fluidity compared with untreated MSCs. Nevertheless, depletion of cholesterol or downregulation of the CAV-1 gene both independently decreased the membrane cholesterol level (Fig. 3) and increased membrane fluidity (Fig. 5) compared with their control counterparts.

The presence of cholesterol in the plasma membrane is important not only for membrane fluidity and structure, but also for cell adhesion. A possible role for cholesterol and membrane lipids in controlling cell morphology and motility has been previously reported [45-47]; however, their possible involvement in regulating cell adhesion is unexplored. A recent study demonstrates that the modification of cholesterol levels in MSC membranes causes significant changes in cell adhesion to $\mathrm{CL}$ and FN, which is directly related to tissue rigidity in humans $[22,25]$. Acute depletion of cholesterol and CAV-1 mRNA in MSCs results in significantly reduced rates of cell adhesion, while cholesterol supplementation results in better cell adhesion (Fig. 6). Previous studies have addressed the factors that contribute to changes in the cell adhesion rate, including ECM structure and components, focal adhesion proteins, and actin cytoskeleton arrangements. Additionally, it has been shown that cholesterol enhances the adhesion of monocytes to the endothelium by translocating cell adhesion molecules-bound to caveolin-1-out of caveolae for more immediate cell-cell interaction [19]. Meanwhile, cholesterol depletion decreases L27 cell adhesion and migration to FN-coated substrates [47] and is known to decrease endothelial cell adhesion on polyacrylamide gel due to increases in the average traction force that cells exert on the substrate. These larger traction forces translate into cell traction activities, which further decrease monolayer stability, adhesion, and cell spreading [17]. In addition to the above, another important factor influencing cell adhesion is integrin expression [23].

Our results show that modification of cholesterol/ CAV-1/caveolae homeostasis is closely related to changes in cell surface integrin levels; these changes are likely, at least in part, responsible for alterations in the cell adhesion rate on CL and FN. Our data demonstrate that the level of integrins per cell is significantly higher on Chol-MSCs compared with other groups (Fig. 7). These Chol-MSCs show higher adhesion rates compared with untreated or M $\beta C D-M S C s$ (Fig. 6), suggesting that excess cholesterol loading on membranes increases both integrin expression level and cell adhesion rate. Integrins are major matrix-adhesive, mechanosensing receptors for cell substrates and are involved in MSC substrate rigidity-dependent responses [22, 25, 27]. Since cholesterol/CAV-1/caveolae perturbation affects adhesion processes in MSCs, mediated by changes in integrin availabilities, and the stability of integrin adhesion appears to be important for MSC substrate rigidity sensing, MSC substrate rigidity responses may be sensitive to membrane cholesterol.

Given the critical role of integrins in governing cell morphology [48], membrane cholesterol may therefore play a role in integrin-mediated cell shape changes. In fact, we observed here that changes in cell adhesion and integrin expression levels due to membrane cholesterol modification in MSCs were accompanied by remodeling of the actin cytoskeleton and changes in cell morphology (Fig. 3b). A reduction in membrane cholesterol resulted in rounding of the MSCs and disorganization of the actin networks, shown by phalloidin staining, while the Chol-MSC group were well spread and retained spindle shapes (Fig. 3b). Interestingly, changes in CAV-1/caveolae expression on MSC membranes had no significant effect on changes in cell shape. Further studies are required to better understand cholesterol-mediated cell morphology changes; however, our findings highlight the fact that cholesterol also affects cell morphology, which may be mediated by integrin activities on MSC membranes.

More importantly, overall results from our previous and current studies point out that alterations of biological activities in MSCs using cholesterol may be applied to the use of MSCs in regenerative medicine applications. Modified cell adhesion characteristics can be of relevance to the introduction of MSCs to a biomaterial surface for various types of tissue engineering applications. For example, cells for artificial heart valves or blood vessel engineering are often required to be nonadherent to biomaterials to avoid thrombosis and embolism [49]. Meanwhile, in skeletal muscle or bone tissue engineering, cells need to be adherent to materials used in scaffolds for subsequent proliferation, differentiation, and tissue reconstruction $[50,51]$. Therefore, acute 
treatment of MSCs with either $\mathrm{M} \beta \mathrm{CD}$ or free cholesterol can be a useful tool to adjust adhesion properties of MSCs to optimize the tissue engineering conditions. It has been reported that cholesterol may also affect the MSC differentiation potential, in particular osteogenic differentiation. Previously, we have reported that CAV-1 and cholesterol play an important role in regulating osteogenesis-driven PI3K/Akt signaling in MSCs [32]. Moreover, a study from $\mathrm{Li}$ et al. has reported that cholesterol loading enhances osteoblastic differentiation in mouse MSCs, possibly mediated by induction of BMP2 and RUNX2 expressions [52]. More interestingly, a study from Hamidouche et al. has shown that priming for $\beta 1$ integrin expression in cells strongly enhanced osteogenesis [53]. Taken together, the results from our study additionally suggest that MSCs with increased membrane cholesterol content may respond more sensitively to osteogenic inductions, and therefore result in more efficient bone regeneration.

Recently, several studies have reported evidence that cholesterol-regulating drugs such as statins influence stem cell functions. The statins class of drugs lower the level of cholesterol in the blood by inhibiting the production of the enzyme in the liver that is responsible for cholesterol biosynthesis [54]. Previously, statins have been shown to have a significant beneficial effect on treating cardiovascular- and atherosclerosis-related diseases as well as increasing bone mass [55-57]; however, according to more recent studies, statin therapies may have detrimental effects on stem cell function. For example, Izadpanah and colleagues found that statins significantly reduced the growth rate of MSCs as well as the potential of MSCs to differentiate into macrophages [58]. Others have reported that long-term statin treatment strongly inhibited MSC differentiation into bone, cartilage, and smooth muscle cells, and induced higher apoptotic cell death [59,60]. Results from our study also suggest that a decrease in membrane cholesterol may have negative effects on MSC behavior, particularly on adhesion properties and cytoskeletal organization (Figs. 3 and 6). Although the only report of its kind, a study has suggested that pravastatin therapies to lower cholesterol levels in hypercholesterolemic patients resulted in a significant reduction in erythrocyte and platelet membrane cholesterol content, which further caused changes in the $\mathrm{Na}^{+} / \mathrm{K}^{+}$pump activity in these cells [61]. Whether these changes in membrane cholesterol and function observed during cholesterol lowering also occur in other cells is unknown. Taken together, these studies suggest that cholesterol lowering in stem cells, either by statin treatment or membrane cholesterol depletion, may impose negative effects on stem cell behaviors and activities. Therefore, in future studies, it will be interesting to investigate short- and long-term effects of statin treatments on membrane and intracellular cholesterol levels as well as effects of statins on MSC behavior and function.

\section{Conclusions}

In conclusion, the two important findings of this study are: 1) membrane cholesterol and CAV-1/caveolae in human bone marrow-derived MSCs are directly and functionally linked, such that cholesterol level is regulated by CAV-1/caveolae; and 2) modification of cellular cholesterol/CAV-1/caveolae homeostasis in MSC membranes has significant effects on plasma membrane fluidity, cell adhesion, and cell surface integrin levels. Membrane cholesterol depletion in MSCs results in reductions in CAV-1 mRNA and protein expression, the number of caveolae, the adhesion rate to $\mathrm{CL}$ and FN, and cell surface integrin levels, and, in turn, causes increased membrane fluidity. Cholesterol enrichment has the exact opposite effects. These observations underscore the importance and possibility of cholesterol in controlling and regulating the biological activities of MSCs. In a broader context, since cholesterol is a major health concern particularly in the US and is easily and frequently managed, results from this study could be applied to treatments for diseases which involve cholesterol or lipid organization disorders and to manipulate biological activities of MSCs for cell therapy and/or tissue engineering, especially for bone tissue engineering.

\section{Additional file}

Additional file 1: Table S1. Cell groups used in this study. Each cell group was generated by pooling MSCs from three to four donors. Donor MSCs are specified by age (number) and gender ( $m$, male; $f$, female). (PDF $14 \mathrm{~kb}$ )

\section{Abbreviations}

2D: Two-dimensional; APC: Allophycocyanin; BSA: Bovine serum albumin; CAV-1: Caveolin-1; Chol-MSC: Cholesterol-enriched mesenchymal stem cell; chol-MBCD: Cholesterol-methyl- $\beta$-cyclodextrin inclusion complexes; CL: Collagen I; CS-FBS: Charcoal stripped fetal bovine serum; DMEM: Dulbecco's modified Eagle's medium; ECM: Extracellular matrix; FACS: Fluorescenceactivated cell sorting; FBS: Fetal bovine serum; FGF: Fibroblast growth factor; FN: Fibronectin; HRP: Horseradish peroxidase; ISM: Isolation medium; MSC: Mesenchymal stem cell; MTS: 3-(4,5-Dimethylthiazol-2-yl)-5-(3carboxymethoxyphenyl)-2-(4-sulfophenyl)-2H-tetrazolium; M $\beta C D$ : Methyl- $\beta$ cyclodextrin; M $B C D-M S C$ : Cholesterol-depleted mesenchymal stem cell; PBS: Phosphate-buffered saline; PCR: Polymerase chain reaction; PE: Phycoerythrin; PFA: Paraformaldehyde; PI3K: Phosphoinositide 3kinase; PL: Plain cell culture plastic; PM: Proliferation medium; PVDF: Polyvinylidene fluoride; si CAV-1-MSC: Mesenchymal stem cell transfected with caveolin-1 small interfering RNA; si Ctrl-MSC: Mesenchymal stem cell transfected with control, nonspecific small interfering RNA; TBST: Trisbuffered saline $+0.05 \%$ Tween 20

\section{Acknowledgements}

The authors would like to thank Dr. Paul Manner (University of Washington) for providing surgical biospecimens, and Dr. Jian Tan (University of Pittsburgh) for isolation of MSCs. 


\section{Funding}

This project was funded by the National Institutes of Health (1R01 EB019430).

\section{Availability of data and materials}

The datasets used and/or analyzed during the current study are available from the corresponding author upon reasonable request.

\section{Authors' contributions}

Conception and design: JS and RST; collection and/or assembly of data: JS, MRF, and RST; data analysis and interpretation: JS, HL, and RST; provision of study materials: JS, HL, and RST; manuscript writing and/or editing: JS, HL, MRF, and RST. All authors provided input for the final submitted manuscript, and all authors read and approved the final manuscript.

\section{Ethics approval and consent to participate}

Human bone marrow-derived MSCs were isolated with Institutional Review Board approval (PRO-13030393) from the femoral heads of patients undergoing total hip arthroplasty, obtained with informed consent.

\section{Consent for publication}

Not applicable.

\section{Competing interests}

The authors declare that they have no competing interests.

\section{Publisher's Note}

Springer Nature remains neutral with regard to jurisdictional claims in published maps and institutional affiliations.

Received: 17 January 2018 Revised: 3 March 2018 Accepted: 8 March 2018 Published online: 03 April 2018

\section{References}

1. Pittenger MF, Mackay AM, Beck SC, et al. Multilineage potential of adult human mesenchymal stem cells. Science. 1999;284:143-7.

2. Reyes $M$, Lund $T$, Lenvik $T$, et al. Purification and ex vivo expansion of postnatal human marrow mesodermal progenitor cells. Blood. 2001;98: 2615-25.

3. Baksh D, Yao R, Tuan RS. Comparison of proliferative and multilineage differentiation potential of human mesenchymal stem cells derived from umbilical cord and bone marrow. Stem Cells. 2007;25:1384-92.

4. Aggarwal S, Pittenger MF. Human mesenchymal stem cells modulate allogeneic immune cell responses. Blood. 2005;105:1815-22.

5. Pistoia $V$, Raffaghello L. Mesenchymal stromal cells and autoimmunity. Int Immunol. 2017;29:49-58.

6. Engler AJ, Sen S, Sweeney HL, et al. Matrix elasticity directs stem cell lineage specification. Cell. 2006;126:677-89.

7. Allen JA, Halverson-Tamboli RA, Rasenick MM. Lipid raft microdomains and neurotransmitter signalling. Nat Rev Neurosci. 2007;8:128-40.

8. Nicolau DV Jr, Burrage K, Parton RG, et al. Identifying optimal lipid raft characteristics required to promote nanoscale protein-protein interactions on the plasma membrane. Mol Cell Biol. 2006;26:313-23.

9. Simons K, Toomre D. Lipid rafts and signal transduction. Nat Rev Mol Cell Biol. 2000;1:31-9.

10. Yamada $\mathrm{E}$. The fine structure of the renal glomerulus of the mouse. J Biophys Biochem Cytol. 1955;1:551-66.

11. Smart EJ, Graf GA, McNiven MA, et al. Caveolins, liquid-ordered domains, and signal transduction. Mol Cell Biol. 1999;19:7289-304.

12. Parton RG, Simons K. The multiple faces of caveolae. Nat Rev Mol Cell Biol. 2007:8:185-94

13. Rothberg KG, Heuser JE, Donzell WC, et al. Caveolin, a protein component of caveolae membrane coats. Cell. 1992;68:673-82.

14. Fielding CJ, Fielding PE. Cholesterol and caveolae: structural and functional relationships. Biochim Biophys Acta. 2000;1529:210-22.

15. Fielding CJ, Bist A, Fielding PE. Caveolin mRNA levels are up-regulated by free cholesterol and down-regulated by oxysterols in fibroblast monolayers. Proc Natl Acad Sci U S A. 1997;94:3753-8.

16. Fielding CJ, Bist A, Fielding PE. Intracellular cholesterol transport in synchronized human skin fibroblasts. Biochemistry. 1999;38:2506-13.
17. Norman LL, Oetama RJ, Dembo M, et al. Modification of cellular cholesterol content affects traction force, adhesion and cell spreading. Cell Mol Bioeng. 2010;3:151-62.

18. Dawaliby R, Trubbia C, Delporte C, et al. Phosphatidylethanolamine is a key regulator of membrane fluidity in eukaryotic cells. J Biol Chem. 2016;291: 3658-67.

19. Fu C, He J, Li C, et al. Cholesterol increases adhesion of monocytes to endothelium by moving adhesion molecules out of caveolae. Biochim Biophys Acta. 2010;1801:702-10.

20. Humphries JD, Byron A, Humphries MJ. Integrin ligands at a glance. J Cell Sci. 2006;119:3901-3.

21. Du J, Zu Y, Li J, et al. Extracellular matrix stiffness dictates Wnt expression through integrin pathway. Sci Rep. 2016;6:20395.

22. Swift J, Ivanovska IL, Buxboim A, et al. Nuclear lamin-A scales with tissue stiffness and enhances matrix-directed differentiation. Science. 2013;341:1240104.

23. Chen $\mathrm{S}$, Lewallen $M$, Xie T. Adhesion in the stem cell niche: biological roles and regulation. Development. 2013;140:255-65.

24. Kanchanawong P, Shtengel G, Pasapera AM, et al. Nanoscale architecture of integrin-based cell adhesions. Nature. 2010;468:580-4.

25. Du J, Chen $X$, Liang $X$, et al. Integrin activation and internalization on soft ECM as a mechanism of induction of stem cell differentiation by ECM elasticity. Proc Natl Acad Sci U S A. 2011;108:9466-71.

26. Vassilieva EV, Gerner-Smidt K, Ivanov Al, et al. Lipid rafts mediate internalization of beta1-integrin in migrating intestinal epithelial cells. Am J Physiol Gastrointest Liver Physiol. 2008;295:G965-76.

27. Yeh YC, Ling JY, Chen WC, et al. Mechanotransduction of matrix stiffness in regulation of focal adhesion size and number: reciprocal regulation of caveolin-1 and beta1 integrin. Sci Rep. 2017;7:15008.

28. del Pozo MA, Balasubramanian N, Alderson NB, et al. Phospho-caveolin-1 mediates integrin-regulated membrane domain internalization. Nat Cell Biol. 2005;7:901-8.

29. Ning Y, Buranda T, Hudson LG. Activated epidermal growth factor receptor induces integrin alpha2 internalization via caveolae/raft-dependent endocytic pathway. J Biol Chem. 2007:282:6380-7.

30. Caterson EJ, Nesti LJ, Danielson KG, et al. Human marrow-derived mesenchymal progenitor cells: isolation, culture expansion, and analysis of differentiation. Mol Biotechnol. 2002;20:245-56.

31. Viscardi RM, Ullsperger S, McKenna MC. Carbon stripping extracts serum free fatty acids: implications for media supplementation of cultured type ॥ pneumocytes. Lab Invest. 1991;65:250-7.

32. Baker N, Sohn J, Tuan RS. Promotion of human mesenchymal stem cell osteogenesis by PI3-kinase/Akt signaling, and the influence of caveolin-1/ cholesterol homeostasis. Stem Cell Res Ther. 2015;6:238.

33. Petkovic M, Vocks A, Muller $M$, et al. Comparison of different procedures for the lipid extraction from HL-60 cells: a MALDI-TOF mass spectrometric study. Z Naturforsch C. 2005;60:143-51.

34. Gopalakrishna P, Chaubey SK, Manogaran PS, et al. Modulation of alpha5beta1 integrin functions by the phospholipid and cholesterol contents of cell membranes. J Cell Biochem. 2000:77:517-28.

35. Song KS, Li S, Okamoto T, et al. Co-purification and direct interaction of Ras with caveolin, an integral membrane protein of caveolae microdomains. Detergentfree purification of caveolae microdomains. J Biol Chem. 1996;271:9690-7.

36. Baker N, Zhang G, You Y, et al. Caveolin-1 regulates proliferation and osteogenic differentiation of human mesenchymal stem cells. J Cell Biochem. 2012:113:3773-87.

37. Zidovetzki R, Levitan I. Use of cyclodextrins to manipulate plasma membrane cholesterol content: evidence, misconceptions and control strategies. Biochim Biophys Acta. 2007;1768:1311-24.

38. Frank PG, Cheung MW, Pavlides S, et al. Caveolin-1 and regulation of cellular cholesterol homeostasis. Am J Physiol Heart Circ Physiol. 2006:291:H677-86.

39. Yao $Y$, Hong $S$, Zhou $H$, et al. The differential protein and lipid compositions of noncaveolar lipid microdomains and caveolae. Cell Res. 2009;19:497-506.

40. Lee JW, Juliano R. Mitogenic signal transduction by integrin- and growth factor receptor-mediated pathways. Mol Cells. 2004;17:188-202.

41. Peres C, Yart A, Perret B, et al. Modulation of phosphoinositide 3-kinase activation by cholesterol level suggests a novel positive role for lipid rafts in lysophosphatidic acid signalling. FEBS Lett. 2003;534:164-8.

42. Park JH, Lee MY, Han HJ. A potential role for caveolin-1 in estradiol-17betainduced proliferation of mouse embryonic stem cells: involvement of Src, PI3K/Akt, and MAPKs pathways. Int J Biochem Cell Biol. 2009;41:659-65. 
43. Hailstones D, Sleer LS, Parton RG, et al. Regulation of caveolin and caveolae by cholesterol in MDCK cells. J Lipid Res. 1998;39:369-79.

44. Sanchez-Wandelmer J, Davalos A, Herrera E, et al. Inhibition of cholesterol biosynthesis disrupts lipid raft/caveolae and affects insulin receptor activation in 3T3-L1 preadipocytes. Biochim Biophys Acta. 2009;1788:1731-9.

45. Sun M, Northup N, Marga F, et al. The effect of cellular cholesterol on membrane-cytoskeleton adhesion. J Cell Sci. 2007;120:2223-31.

46. Hoque M, Rentero C, Conway JR, et al. The cross-talk of LDL-cholesterol with cell motility: insights from the Niemann Pick Type C1 mutation and altered integrin trafficking. Cell Adh Migr. 2015;9:384-91.

47. Ramprasad OG, Srinivas G, Rao KS, et al. Changes in cholesterol levels in the plasma membrane modulate cell signaling and regulate cell adhesion and migration on fibronectin. Cell Motil Cytoskeleton. 2007;64:199-216.

48. Hood JD, Cheresh DA. Role of integrins in cell invasion and migration. Nat Rev Cancer. 2002:2:91-100.

49. Khalili AA, Ahmad MR. A review of cell adhesion studies for biomedical and biological applications. Int J Mol Sci. 2015;16:18149-84.

50. Syverud BC, Lee JD, VanDusen KW, et al. Isolation and purification of satellite cells for skeletal muscle tissue engineering. J Regen Med. 2014;3.

51. Marolt $D$, Knezevic M, Novakovic GV. Bone tissue engineering with human stem cells. Stem Cell Res Ther. 2010;1:10.

52. Li H, Guo H, Li H. Cholesterol loading affects osteoblastic differentiation in mouse mesenchymal stem cells. Steroids. 2013;78:426-33.

53. Hamidouche $Z$, Fromigue $\mathrm{O}$, Ringe J, et al. Priming integrin alpha5 promotes human mesenchymal stromal cell osteoblast differentiation and osteogenesis. Proc Natl Acad Sci U S A. 2009:106:18587-91.

54. Sirtori CR. The pharmacology of statins. Pharmacol Res. 2014;88:3-11.

55. Zhou Q, Liao JK. Statins and cardiovascular diseases: from cholesterol lowering to pleiotropy. Curr Pharm Des. 2009;15:467-78.

56. Mundy GR. Statins and their potential for osteoporosis. Bone. 2001;29:495-7.

57. Mundy G, Garrett R, Harris $S$, et al. Stimulation of bone formation in vitro and in rodents by statins. Science. 1999;286:1946-9.

58. Izadpanah $R$, Schachtele DJ, Pfnur AB, et al. The impact of statins on biological characteristics of stem cells provides a novel explanation for their pleiotropic beneficial and adverse clinical effects. Am J Physiol Cell Physiol. 2015;309:C522-31.

59. Kupcsik L, Meurya T, Flury M, et al. Statin-induced calcification in human mesenchymal stem cells is cell death related. J Cell Mol Med. 2009;13:4465-73.

60. Kim KH, Kim YM, Lee MJ, et al. Simvastatin inhibits sphingosylphosphorylcholine-induced differentiation of human mesenchymal stem cells into smooth muscle cells. Exp Mol Med. 2012;44:159-66.

61. Lijnen P, Echevaria-Vazquez D, Petrov V. Influence of cholesterol-lowering on plasma membrane lipids and function. Methods Find Exp Clin Pharmacol. 1996:18:123-36.

\section{Submit your next manuscript to BioMed Central and we will help you at every step:}

- We accept pre-submission inquiries

- Our selector tool helps you to find the most relevant journal

- We provide round the clock customer support

- Convenient online submission

- Thorough peer review

- Inclusion in PubMed and all major indexing services

- Maximum visibility for your research

Submit your manuscript at www.biomedcentral.com/submit

C) Biomed Central 